\title{
A ortodoxia neoclássica
}

\author{
ELEUTÉRIO F. S. PRADO
}

$\mathrm{O}$ EXAME da influência do pensamento econômico neoclássico no assim chamado pensamento econômico brasileiro é uma tarefa que exige uma pesquisa de grande fôlego (1). Neste artigo temos um objetivo modesto que se concentra na difusão da teoria neoclássica na formação dos economistas no Brasil. Fazemos isso, ademais, de maneira restrita pois examinamos a questão focando apenas os dois centros de pós-graduação mais antigos do Brasil: a Escola de Pós-Graduação em Economia da Fundação Getúlio Vargas (EPGE) e o Instituto de Pesquisas Econômicas (IPE) da Faculdade de Economia e Administração da Universidade de São Paulo (FEA-USP).

Com este objetivo, aproveitamos pesquisas e escritos de outros autores (2) e investigamos alguns aspectos da história da influência da teoria neoclássica no ambiente acadêmico brasileiro, examinando os fundamentos teóricos dos artigos publicados nas revistas acadêmicas dos dois centros mencionados - ou seja, na Revista Brasileira de Economia (RBE) e na revista Estudos Econômicos (EE), respectivamente. Na impossibilidade de desenvolver um estudo abrangente, fazemos a suposição de que um exame das fontes geradoras do pensamento teórico neoclássico possa fornecer uma idéia sobre o seu espraiamento mais geral.

Esta escolha se justifica porque esses dois centros desempenharam um papel importante na difusão da teoria neoclássica no Brasil - papel este que foi mesmo central nos primórdios da criação dos cursos de pós-graduação em Economia. Mais recentemente, com o aumento do número de centros de pós-graduação, ao mesmo tempo em que declina a influência do IPE como núcleo difusor do pensamento neoclássico, torna-se crescente neste aspecto o papel desempenhado por outros centros como a Pontifícia Universidade Católica do Rio de Janeiro (PUCRJ) e a Universidade de Brasília (UNB).

Para poder examinar a difusão das concepções neoclássicas na formação teórica dos economistas brasileiros, buscamos apresentar de início uma caracterização sumária dessa teoria. Em seqüência, mostramos os resultados da pesquisa sobre os fundamentos teóricos dos artigos publicados nas revistas RBE e EE, interpretando-os a luz de um conhecimento mais amplo sobre a evolução dos centros de pós-graduação da EPGE e do IPE. Tecemos também nessa seção alguns comentários mais gerais sobre o processo de difusão da teoria neoclássica nos cursos de graduação e de pós-graduação no Brasil. Ao final, apresentamos nossas conclusões. 


\section{Características gerais}

Para definir os contornos da teoria neoclássica, é preciso contrapô-la à teoria clássica. Esta última caracteriza-se por analisar o sistema econômico principalmente no âmbito da produção, e numa perspectiva de longo prazo (3). Nessa situação em que se faz abstração dos desequilíbrios e das flutuações de curto prazo, as taxas de lucro calculadas em relação aos preços de oferta dos bens de capital são uniformes, assim como são uniformes as remunerações da força de trabalho e dos recursos naturais considerados qualitativamente homogêneos. Pressupõe-se que haja livre competição, e que não existam barreiras à entrada nas diversas indústrias. No estado de longo prazo, os preços são ditos naturais ou de produção, porque refletem as condições de reprodução da economia capitalista de mercado.

Os economistas clássicos, assim como Marx, acreditavam que o sistema econômico funcionava sob uma lei de tendência à igualação das taxas de lucro nos diferentes setores e ramos da economia. Segundo eles, os capitais, principalmente na forma monetária, saiam dos ramos com taxas de lucro mais baixas, para entrar naqueles com taxas de lucro acima da média. E isto ocorria devido à ação dos empresários capitalistas que buscavam persistentemente a valorização de seus capitais no mais alto nível possível. Dada a alta mobilidade do capital e uma certa mobilidade da força de trabalho, a alocação dos capitais nos diversos setores industriais e agrícolas acabava gerando uma tendência para a uniformização das taxas lucro e das remunerações dos demais agentes da produção. Neste sentido, os preços de produção apareciam para eles, ao mesmo tempo, como possibilidades que são reais porém improváveis. De qualquer modo, eles funcionavam como centros de gravidade dos preços de mercado, que supostamente refletiam as condições contingentes do processo econômico em cada lugar e a cada momento do tempo.

No que se refere à repartição, a teoria clássica caracterizava-se por uma falta de assimetria no tratamento das diferentes parcelas recebidas pelas diversas classes sociais. A longo prazo, os salários mais baixos da escala de remunerações tendiam a ser determinados pelo nível social de subsistência; fora desse estado, eles flutuavam em torno desse valor, em função da demanda e da oferta de força de trabalho. Deduzindo do montante das vendas efetivadas nos mercados os salários pagos, assim como os valores necessários para repor os meios de produção gastos no processo produtivo, chegavam aos lucros, que eram vistos como um excedente, mediante o qual os capitalistas remuneravam as classes possuidoras: fossem eles próprios proprietários do capital, fossem os proprietários dos recursos naturais empregados na produção. Assim, a renda da terra era determinada, segundo eles, pela possibilidade de remuneração daquelas parcelas de solo menos férteis, mais distantes etc. que podiam ser empregadas na agricultura e na pecuária somente na falta de parcelas melhores, e que eram chamadas, por isso, de marginais. 
A teoria neoclássica tradicional - de Marshall, Jevons, Walras, Menger etc. -, nascida na última terça parte do século XIX como um desvio de curso que vai se afastando progressivamente da corrente da teoria clássica, continuou analisando a economia capitalista dentro do mesmo contexto de longo prazo. Entretanto, ela modificou algo essencial na tradição de que se originou, mas com a qual veio romper. A mudança fundamental desse novo curso de análise econômica, que não parou de engrossar durante todo o século XX, deu-se na teoria da repartição.

Dessa forma, a marca distintiva da teoria neoclássica - ou das teorias neoclássicas, para ser mais preciso - vem a ser o tratamento simétrico dado às diversas parcelas da renda. Assim, os salários, os lucros e as rendas passam a ser vistos como partes determinadas pelas interseções das ofertas e das demandas, em níveis que se igualam, sob a suposição de que a economia se encontra em

... a teoria neoclássica teve desde o início o objetivo de mostrar como um mercado funciona ... equilíbrio, aos valores dos produtos marginais dos chamados serviços. A força de trabalho, os recursos naturais e os meios de produção reprodutíveis (também chamados de capitais físicos) vêm a ser denominados indistintamente fatores de produção. Como tais, eles passam a ser vistos como capazes de gerar serviços que contribuem para a efetivação do processo produtivo. Dentro desse suposto, as chamadas "condições marginais" tornaram-se, então, associadas às remunerações de todas as classes sociais, agora vistas indistintamente como fornecedoras de serviços.

Essa teoria neoclássica em sentido amplo nasceu em diversos países, sob culturas econômicas algo diferentes, quase ao mesmo tempo - ou seja, na década de 1870. Entre os pioneiros acham-se Hermann Heinrich Gossen, na Alemanha; Carl Menger, na Áustria; Léon Walras, na Suíça; Stanley Jevons e Alfred Marshall, na Inglaterra. Todos esses autores centraram sua análise num indivíduo genérico isento de relações sociais, que busca atender ao seu próprio interesse, e que se orienta invariavelmente por suas preferências subjetivas. Sobre essa base, erigiram o que veio a ser chamado de microeconomia, um ramo da teoria econômica que se concentrou inicialmente na análise do mercado de concorrência, no qual cada agente econômico pode ser tratado como independente dos demais. A teoria neoclássica, em geral, teve desde o início o objetivo central de mostrar como um mercado funciona quando tais átomos sociais dançam, por assim dizer, a música dos preços.

Devido a tudo isso, os diversos ramos da teoria neoclássica costumam ser classificados pela origem geográfica, distinguindo-se, então, as escolas francesas, inglesas e austríacas pelo menos (4). Entretanto, ao se procurar uma compreen- 
são mais profunda da origem intelectual dessa teoria, não se pode deixar de considerar o tratamento que os diferentes autores deram ao conceito de capital. Isto porque a motivação mais profunda para a criação dessa teoria veio a ser o desvinculamento dos lucros e da origem dos lucros do movimento ilimitado da acumulação de capital. Esta conexão, que aparece de modo mais ou menos velado nas obras dos economistas clássicos, havia alcançado nos textos de Marx um sentido muito claro. Marx estabelecera uma relação de imanência entre a exploração e a pobreza relativa da classe operária com o movimento sem fim do capital e a conseqüente riqueza crescente dos proprietários dos meios de produção.

Assim, todas as versões da teoria neoclássica partiram da suposição de que a economia é formada por um conjunto de agentes econômicos, e que estes são possuidores, de um lado, de preferências ou escalas de utilidade e, do outro, de dotações de fatores, dentre as quais se incluem determinadas "quantidades de capital". A tarefa, então, de todas elas foi a de mostrar como o "mecanismo de mercado", por meio da produção, da circulação e da repartição, faz um casamento ótimo ou quase ótimo entre o emprego dos fatores e a satisfação dos consumidores. Sem que nenhuma dessas versões tenha deixado de cair em dificuldades, paradoxos e contradições, elas podem ser agrupadas em três: aquelas que conceberam o capital como um fundo de subsistência (Jevons, Böhm-Bawerk e outros), aquelas em que o capital é tratado como um estoque de valor (Wicksell, J. B. Clark, Marshall etc.) e aquelas em que ele é considerado como um simples gênero, constituído por uma coleção de quantidades de bens de produção com diferentes qualidades físicas e que prestam diferentes serviços produtivos (Walras).

Há várias versões da teoria neoclássica em uso atualmente no ensino e na pesquisa em Economia. Há uma versão macroeconômica, que se caracteriza por empregar variáveis agregadas como produto nacional, consumo, renda, quantidade de moeda etc., em especial, a noção de função de produção agregada, na qual entram grosso modo os fatores de produção capital, trabalho e terra. Esta versão originou-se de algum modo sob influência da economia política de Keynes e de sua preocupação característica de tratar o sistema econômico como um todo passível de regulação. Há uma versão microeconômica, em que os fatores de produção são considerados, um a um, como quantidades homogêneas, e os consumidores e as firmas são agentes que tomam decisões individualmente.

É importante notar, nesse ponto, que a própria microeconomia que veio a predominar no final do século XX, e que exerce atualmente uma influência avassaladora no ensino dessa disciplina tem duas versões - uma delas denominada de equilíbrio parcial, e a outra chamada de equilíbrio geral. A primeira, empregada mais na análise de situações concretas, tem sua origem nas formulações teóricas de Marshall, e se preocupa em analisar o consumidor, a firma etc. em relativo isolamento do resto da economia. A segunda versão, mais própria para um estilo 
de teorização platônico, tem as suas raízes nos desenvolvimentos teóricos de Walras, em que todos os mercados são tratados em conjunto. Esta última não analisa a economia em estado de longo prazo, passando a utilizar os conceitos de equilíbrio intertemporal e de equilíbrio temporário.

Em ambas essas versões, entretanto, o capital é tratado como uma coleção de bens. Nos trabalhos empíricos, face à enorme heterogeneidade dos bens de produção, o capital é considerado como um agregado e, nessa condição ambígua, entra na função de produção cuja lógica vem a ser subtrair o tempo do processo de produção.

\section{Difusão no Brasil}

Os primeiros cursos de Economia foram criados no Brasil na década de 40 (5). Ainda que com dificuldades, esses cursos nasceram porque se desejava difundir no país o estudo da Economia como ciência positiva, construída de um modo ou outro sob o fundamento da racionalidade instrumental. Entretanto, em virtude das deficiências de formação dos professores então existentes, neles se misturavam de modo eclético o ensino de administração, contabilidade, direito e ciências sociais em geral (6). A difusão e a consolidação da teoria econômica na formação dos economistas profissionais só ocorreu a partir dos anos 70, acompanhando a expansão, no Brasil, dos cursos de graduação em Economia e dos cursos superiores em geral. Essa difusão ocorreu sob a orientação de currículos mínimos instituídos pelo Ministério da Educação, até recentemente de caráter obrigatório. Ainda que esses currículos tenham sempre sido elaborados sob uma perspectiva ampla, que contempla o ensino de História e de outras ciências sociais, eles nunca deixaram de estar centrados no ensino de Microeconomia e Macroeconomia, disciplinas nas quais os conteúdos neoclássicos ganham proeminência praticamente sem alternativas. Além disso, contemplaram invariavelmente significativa carga de $\mathrm{Ma}$ temática e Estatística, disciplinas estas necessárias à formação ortodoxa.

É preciso ver que, na segunda metade do século XX, a Economia como ciência ganhou um caráter técnico e profissional no mundo todo à medida que o sistema capitalista em permanente expansão foi se tornando gradualmente mais e mais regulado (7). E essa transformação ocorreu não apenas nos meios científicos produtores da ciência, mas também, em simbiose, nos centros dedicados à economia aplicada e nas instituições de ensino de graduação e pós-graduação. Para tanto, desenvolveu-se, sob a hegemonia incontestada dos Estados Unidos, um padrão de pesquisa e de método em Economia, assim como um padrão de estrutura curricular e de ensino de Economia que se espalhou praticamente pelo mundo todo. Ora, é sob o peso dessa dominação que se deu a expansão dos cursos de Economia no Brasil. Vale mencionar, ademais, que essa tendência recebeu aqui um reforço já que, no Brasil, o ensino de graduação em geral é baseado em carreiras profissionais bem demarcadas. 
Em 1966, um grupo de importantes economistas, alguns ligados à ditadura militar implantada havia dois anos, procurou encontrar os caminhos da consolidação do ensino de Economia no país, nos moldes anteriormente aludidos (8). Reunidos no Encontro de Itaipava (RJ), Antônio Delfim Netto, Mário Henrique Simonsen, Isaac Kerstenetsky, entre outros, traçaram novos rumos para o desenvolvimento da ciência econômica no país, visando a emancipá-los do domínio até então exercido por outras disciplinas como Sociologia, Direito, Administração etc. Determinaram, então, como principais objetivos reformular os currículos dos cursos de Economia e iniciar a formação e treinamento de professores para esses cursos mediante a criação de centros de pós-graduação no Brasil, e treinamento de estudantes e docentes, inclusive por meio da realização de doutorado no exterior, especialmente nos Estados Unidos. A finalidade era, segundo Delfim Netto, "estabelecer as condições de um ensino que cubra as partes essenciais da moderna teoria econômica”.

Para atingir esses objetivos, no final dos anos 60 e começo dos 70 foram enviados dezenas de jovens graduados em Economia para estudar no exterior, muitos dos quais financiados por recursos ligados ao Acordo MEC-USAID. Os "peagadês" brasileiros, como vieram a ser chamados, que voltaram na década de 70 , instalaram-se principalmente em instituições estritamente de pesquisa, como o IBRE (Instituto Brasileiro de Economia) e o IPEA (Instituto de Pesquisa Econômica Aplicada), ou em instituições mistas de pesquisa e ensino, como o IPE e a EPGE. Uma parte menor espalhou-se pelos novos cursos de pós-graduação das universidades federais, formando núcleos de pesquisa que não raramente se vinculavam também a órgãos de gestão, planejamento e desenvolvimento econômico, seja do governo federal seja de governos estaduais.

Passados mais de 30 anos do encontro de Itaipava, uma questão interessante é saber se o esforço de internacionalização da prática e do ensino de Economia no Brasil, sob a égide da teoria neoclássica, alcançou os seus objetivos. Não há dúvida de que houve uma enorme difusão dos padrões de ensino e pesquisa da teoria econômica ortodoxa nos cursos de graduação e pós-graduação do Brasil, mas isto não ocorreu sem resistência. Quando se olha o conjunto dos centros pós-graduação no Brasil que participam da ANPEC (Associação Nacional dos Centros de Pós-graduação em Economia) - quase 20 neste final de milênio - vê-se, como mostrou Anuatti (1997), que há um grande equilíbrio em termos de orientação teórica. Como se sabe, em cerca de metade desses centros, há um predomínio da teoria neoclássica, mas na outra metade há uma influência importante do estruturalismo cepalino, dos vários marxismos, das correntes keynesianas heterodoxas, do neo-ricardianismo etc.

Esse relativo equilíbrio revela-se também no caráter aberto e pluralista dos congressos anuais da ANPEC, nos quais participam lado a lado professores e pes- 
quisadores de Economia das mais diversas orientações teóricas e dos mais variados matizes ideológicos. É bem revelador, ademais, que esses encontros venham sendo realizados em associação - e em relativa harmonia - com a SBE (Sociedade Brasileira de Econometria), de orientação mais ortodoxa, e com a SEP (Sociedade Brasileira de Economia Política), de orientação predominantemente heterodoxa.

Não é, porém, apenas por meio da influência exercida no ensino de graduação e pós-graduação que se pode avaliar o sucesso do esforço de internacionalização antes referido. Os seus objetivos só teriam sido plenamente alcançados na medida em que se consolidasse no país uma produção teórica que seguisse os padrões internacionais, na forma e no conteúdo, e que fosse predominantemente neoclássica. Para verificar se isto ocorreu - ou melhor, para saber em que medida isto vem ocorrendo - examinamos os conteúdos teóricos da Revista Brasileira de Economia, da Fundação Getúlio Vargas, e da revista Estudos Econômicos, do Instituto de Pesquisas Econômicas, da Universidade de São Paulo.

Classificamos os artigos dessas revistas em cinco categorias: teoria microeconômica, microeconomia aplicada, teoria macroeconômica, macroeconomia aplicada e os outros. Nas duas primeiras, incluímos apenas aqueles artigos que seguem explicita e intencionalmente uma orientação neoclássica, seja no estilo tradicional anteriormente aludido, seja no estilo do modelo de Arrow e Debreu. Nas duas categorias seguintes, incluímos os artigos da área de macroeconomia claramente ligados à chamada síntese neoclássica. Na categoria de “outros”, colocamos os artigos meramente descritivos, heterodoxos, históricos etc., incluindo aí aqueles que apresentam uma orientação neoclássica apenas difusa (9). No caso da revista Estudos Econômicos, por razões que ficarão claras, separamos numa categoria própria os artigos de História Econômica. Apresentamos as informações coletadas em décadas, registrando, também, o número de publicações assinadas por autores estrangeiros.

A revista Estudos Econômicos nasceu em abril de 1970 com o nome bem mais pretensioso de Revista de Teoria e Pesquisa Econômica. Após a edição dos dois primeiros números, adotou o nome atual, passando a ter como objetivo explícito publicar contribuições de interesse teórico mas, principalmente, análises de problemas concretos da economia brasileira.

A tabela que aparece em seqüência mostra claramente que apenas na década de 70 houve um empenho sério de publicação de textos com conteúdo neoclássico na revista Estudos Econômicos. Esta foi a década da volta da maioria dos "peagadês" que haviam ido estudar no exterior e que já eram do IPE ou vieram para o Instituto. Consultando os números da revista dessa década, podemos encontrar muitos artigos dos jovens doutores recém-chegados, ao lado de artigos de professores estrangeiros, muitos dos quais, de alguma forma, colaboraram na formação desse centro de pós-graduação. 
$\mathrm{Na}$ década seguinte, praticamente desapareceram os artigos de microeconomia, reduzindo-se sensivelmente a presença de artigos de macroeconomia neoclássica. É um fato notório que os "peagadês" do IPE, com o fim da ditadura e com a redução das verbas de pesquisa disponíveis, passaram a se interessar por outras atividades, não-acadêmicas, tais como o exercício de poder tecnocrático nos aparelhos de Estado e/ou, simplesmente, o enriquecimento pessoal no mercado financeiro, na iniciativa privada etc.

Tabela 1. Conteúdo da revista Estudos Econômicos (em \%)

\begin{tabular}{l|c|c|c}
\hline \multicolumn{1}{c|}{ Temas } & \multicolumn{3}{|c}{ Décadas } \\
\hline Teoria Microeconômica & $1970-80$ & $1981-90$ & $1991-2000$ \\
Microeconomia Aplicada & 5,3 & 0,7 & 0 \\
Teoria Macroeconômica & 9,6 & 2,0 & 1,9 \\
Macroeconomia Aplicada & 12,0 & 3,4 & 2,4 \\
Outros & 15,0 & 6,8 & 7,2 \\
História Econômica & 46,1 & 53,9 & 74,6 \\
Autores estrangeiros & 12,0 & 33,1 & 13,9 \\
N. ${ }^{o}$ total de artigos publicados & 29,9 & 19,8 & 6,7 \\
\hline
\end{tabular}

Na falta de artigos de Teoria Econômica, ou mesmo de Economia Aplicada, sem grandes compromissos teóricos, começaram então a ser publicados artigos de História Econômica, dando expressão assim a um núcleo sério e consistente de historiadores que havia se formado, ao longo dos anos, no Departamento de Economia da Faculdade de Economia e Administração da USP. Se a participação de artigos escritos por professores de outros países ainda foi expressiva na década de 80 , isto se deveu ao esforço dos editores, liderados pelo profesor Iraci Costa, em obter colaborações de historiadores estrangeiros que estavam investigando o passado do Brasil.

$\mathrm{Na}$ década seguinte, o ímpeto desses historiadores reduziu-se e a revista Estudos Econômicos passou a publicar, cada vez mais, artigos heterodoxos. Nessa década, foi a vez principalmente da área de Metodologia da Economia e de História do Pensamento Econômico, constituída por um núcleo heterogêneo de doutores formados no Brasil, o qual conseguiu continuar dando expressão acadêmica ao IPE em nível nacional. Muitos dos antigos "peagadês" se aposentaram ou simplesmente abandonaram a FEA no fim dos anos 80 e durante a década de 90. A FEA continua tendo um núcleo de economistas neoclássicos, muitos dos quais, orientados pela 
geração formada no exterior, obtiveram o doutorado no próprio IPE, mas passaram a dedicar-se principalmente à elaboração de pesquisas contratadas. Em conseqüência disso, o IPE neoclássico deixou, pouco a pouco, nessas duas décadas, de ter uma expressão significativa no mundo acadêmico dos economistas brasileiros.

Uma história diferente emerge das informações que se podem obter consultando as quase seis décadas de existência da Revista Brasileira de Economia, criada em 1947 para "preencher um lugar vago" e para publicar "estudos científicos, teóricos e aplicados", segundo Simões Lopes, então presidente da FGV. O exame da tabela que aparece em seqüência demonstra que o esforço da EPGE para criar um pensamento econômico ortodoxo no Brasil foi persistente. Com exceção da década de 60, o número de artigos publicados nas áreas de microeconomia e macroeconomia manteve-se bastante expressivo.

Tabela 2. Conteúdo da Revista Brasileira de Economia (em \%)

\begin{tabular}{l|rrrrrr}
\hline & \multicolumn{5}{|c}{ Décadas } \\
\hline \multicolumn{1}{c|}{ Temas } & $1947-49$ & $1950-59$ & $1960-69$ & $1970-79$ & $1980-89$ & $1990-00$ \\
\hline Teoria Microeconômica & 0 & 8,9 & 0,7 & 2,7 & 5,7 & 3,7 \\
Microeconomia Aplicada & 3,5 & 1,6 & 3,6 & 2,7 & 8,3 & 9,1 \\
Teoria Macroeconômica & 37,9 & 26,0 & 7,3 & 12,8 & 16,1 & 4,5 \\
Macroeconomia Aplicada & 27,6 & 5,7 & 8,8 & 11,5 & 23,8 & 20,2 \\
Outros & 31,0 & 57,7 & 79,6 & 70,3 & 46,1 & 62,4 \\
Autores estrangeiros & 34,5 & 61,8 & 38,0 & 22,6 & 8,3 & 7,0 \\
N. ${ }^{o}$ total artigos publicados & $\mathbf{2 9}$ & $\mathbf{1 2 3}$ & $\mathbf{1 3 7}$ & $\mathbf{2 2 6}$ & $\mathbf{1 9 3}$ & $\mathbf{2 4 2}$ \\
\hline
\end{tabular}

Nos primeiros anos, que vão da criação dessa revista até o final da década de 50 , podemos observar que o esforço principal se concentrou na publicação de artigos teóricos, muitos dos quais escritos por autores estrangeiros. Mas, isto não ocorreu apenas nas áreas de microeconomia e macroeconomia. Contados na categoria de "outros", encontram-se muitos artigos e conferências de natureza teórica sobre o tema desenvolvimento, geralmente expressando uma visão ortodoxa. Esses dados revelam, pois, um empenho muito consciente em criar e consolidar um núcleo difusor de pensamento neoclássico, capaz de reproduzir aqui os padrões da teoria econômica dominante, principalmente nos países desenvolvidos de língua inglesa. Em segundo lugar, é preciso lembrar que estes foram os anos da chamada controvérsia entre monetaristas e estruturalistas, na qual a RBE teve um papel bastante importante. 
Nas duas décadas do período militar, que vai de 1964 até a transição democrática em 1984, caiu a participação de autores estrangeiros no volume de artigos publicados pela RBE. O compromisso com a divulgação das teorias ortodoxas atenuou-se, e ela passou a publicar um número expressivo de artigos de autores

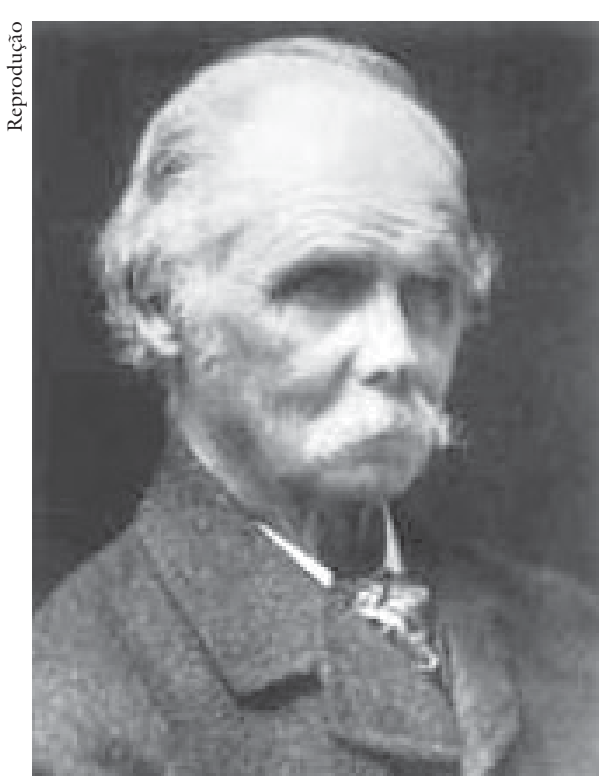

Alfred Marshall (1842-1924) brasileiros comprometidos com a política econômica de curto prazo e o planejamento da atividade econômica de longo prazo. A diversidade temática e ideológica se ampliou. A partir dos anos 80 , as questões ligadas ao desenvolvimento perderam terreno para as questões macroeconômicas, refletindo as dificuldades de ajustamento da economia brasileira. Nesse período, por exemplo, encontramos um grande número de artigos sobre inflação na RBE.

Um fato notável foi a queda persistente da participação de estrangeiros entre os autores que publicaram na RBE ao longo das décadas. É preciso notar que essa participação - tal como ocorreu na revista Estudos Econômicos - dependeu sempre da iniciativa dos editores brasileiros. Estes e as instituições que representavam consideraram, pois, que a publicação de textos de autores já consagrados no exterior era necessária para suprir as carências da produção doméstica, principalmente no aspecto qualitativo. A queda mencionada é, portanto, um indício de que o esforço para criar um pensamento econômico ortodoxo no Brasil foi, em certa medida, bem-sucedido.

\section{Principais conclusões}

Como mostrou Anuatti (1997), a estrutura delineada inicialmente para o sistema de pós-graduação - à EPGE e ao IPE caberia o papel de centro difusor de teoria econômica e aos outros centros menores caberia o desenvolvimento da pesquisa aplicada - não se efetivou historicamente. A divisão do trabalho entre os centros tendeu para um padrão bem mais complexo, em que a competição passou a se travar não só em termos de áreas de concentração, mas também, inclusive, no campo da orientação teórica.

O exame feito por Anuatti dos artigos publicados nos anais da ANPEC, assim como dos programas dos cursos de pós-graduação, mostrou que o pensamento ortodoxo, em mais de 30 anos de luta, não conseguiu obter uma posição de supremacia inconteste no Brasil. 
Em largos traços, podemos dizer que o processo de desenvolvimento do pensamento neoclássico no Brasil teve três fases. A primeira, que vai até o final dos anos 60 e começo dos 70, foi aquela em que se fez um esforço para introduzir o pensamento econômico ortodoxo, assim como os seus padrões de ensino e pesquisa, no ambiente acadêmico brasileiro. Em seqüência, houve uma fase de consolidação que vai até o final dos anos 80 e o princípio da década de 90 . Nessa fase, a produção doméstica de pesquisas teóricas e aplicadas aumentou em quantidade e qualidade, seja nos centros de pós-graduação em Economia seja nos órgãos de pesquisa econômica - federais e estaduais - que se expandiram firmemente no período. O objeto central dos artigos publicados passou a ser a economia brasileira e isto se revela, por exemplo, no número de artigos publicados na área de macroeconomia aplicada.

Após essas duas fases, que podem ser ditas de absorção do pensamento econômico ortodoxo, iniciou-se um período, ora em curso, em que há um notório esforço de integração na comunidade científica internacional - esforço esse que envolve não apenas autores neoclássicos, mas inclui também uma parte dos autores heterodoxos. Tanto a Revista Brasileira de Economia quanto a revista Estudos Econômicos, assim como outras não examinadas aqui, como a Revista de Economia Política, passaram a publicar - e isto é muito significativo - artigos em inglês. Ainda que os temas da economia brasileira continuem tendo uma importância considerável, a forma e o conteúdo dos artigos, assim como a pragmática e a retórica dos discursos, passam cada vez mais a acompanhar os padrões das publicações internacionais.

\section{Notas}

1 Exemplo notável de um estudo desse tipo é o de Bielschowsky (1996).

2 Especialmente Loureiro (1997) e Anuatti Neto (1997).

3 Veja-se sobre o assunto o livro de Kurz \& Salvadori (1995), autores cujo pensamento acompanhamos nesta apresentação sucinta da teoria neoclássica.

4 Ver sobre isso Schumpeter (1954), capítulo 5 da parte 4.

5 Cf. Loureiro (1997), capítulos 1 e 2.

6 Cf. Biderman, Cozac \& Rego (1996).

7 Sobre este ponto, veja-se Prado (1991), especialmente o capítulo 2.

8 As atas do Encontro de Itaipava foram publicadas na Revista Brasileira de Economia, em dezembro de 1966.

9 Os valores absolutos de ambas as tabelas nem sempre são exatos, porque não conseguimos encontrar alguns números dessas revistas. Os valores relativos aí encontrados também não podem ser encarados como indicadores rigorosos, já que a classificação dos artigos envolveu sempre algum grau de imprecisão. 


\section{Referências bibliográficas}

ANUATTI NETO, Francisco. Competição e complementaridade dos centros de pósgraduação em Economia. In: M.R. Loureiro (ed.), 50 anos de Ciência Econômica no Brasil. Petrópolis, Vozes, 1997.

BIDERMAN, Ciro, COZAC, Luiz F L. \& REGO, J.M. Desenvolvimento do ensino de Economia no Brasil. In: Conversas com economistas brasileiros. São Paulo, Ed. 34, 1996.

BIELSCHOWSKY, Ricardo. Pensamento econômico brasileiro: o ciclo ideológico do desenvolvimento. Rio de Janeiro, Contraponto, 1996.

KURZ, Heinz D. \& SALVADORI, Neri. Theory of production: a long-period analysis. Londres, Cambridge University Press, 1995.

LOUREIRO, Maria Rita. Os economistas no governo. Rio de Janeiro, Fundação Getúlio Vargas, 1997.

PRADO, Eleutério F.S. A Economia como ciência. São Paulo, IPE-USP, 1991.

SCHUMPETER, Joseph A. History of economic analysis. New York, Oxford University Press, 1954.

RESUMO - NO ARTIGO enfoca-se a difusão da teoria neoclássica na formação dos economistas brasileiros. Com essa finalidade, apresenta-se de início uma caracterização sumária dessa concepção teórica, que é amplamente dominante em Economia, em quase todo mundo. Em seqüência, faz-se uma análise desse processo com base em resultados de outros autores que examinaram a evolução dos cursos de pós-graduação no Brasil e em pesquisa empírica sobre os fundamentos teóricos dos artigos publicados na Revista Brasileira de Economia e na revista Estudos Econômicos. Nas conclusões, mostra-se que essa difusão já ultrapassou as fases de absorção e de consolidação, tendo entrado agora numa fase caracterizada pela ênfase na integração internacional.

ABSTRACT - THIS PAPER is focused on the diffusion process of the neoclassical theory in the economic background of Brazilian economists. Initially, it presents a brief characterization of this theoretical conception, which is largely dominant all around the world in Economics. After that, it analyzes that diffusion process properly. The analysis is based on results obtained by other researchers that have examined the evolution of graduate courses in Economics in Brazil. At the same time, it is based on empirical research on the theoretical foundations of the papers published in two important Brazilian economic journals: Revista Brasileira de Economia and Estudos Economicos. In the conclusions, it is showed that this diffusion process has left behind the absorption and consolidation phases, and it is getting into another phase, characterized by an emphasis on international integration.

Elentério F. S. Prado é professor-titular da Faculdade de Economia e Administração da Universidade de São Paulo, onde foi chefe do Departamento de Economia no período de agosto de 1994 a julho de 1998. É o autor de Economia como Ciência (IPE-USP, 1991). 